\title{
Assessing the effect of virtual education on information literacy competency for evidence-based practice among the undergraduate nursing students
}

Maryam Shamsaee ${ }^{1}$, Parvin Mangolian shahrbabaki² ${ }^{\mathbb{D}}$, Leila Ahmadian ${ }^{3}$ (D) Jamileh Farokhzadian ${ }^{4^{*}}$ (1) and Farhad Fatehi ${ }^{5,6}$ (D)

\begin{abstract}
Background: Information literacy competency is one of the requirements to implement Evidence-Based Practice (EBP) in nursing. It is necessary to pay attention to curricular development and use new educational methods such as virtual education to strengthen information literacy competency in nursing students. Given the scarcity of the studies on the effectiveness of virtual education in nursing, particularly in Iran, and the positive university atmosphere regarding the use of virtual education, this study investigated the effect of virtual education on the undergraduate nursing students' information literacy competency for EBP.

Methods: This interventional study was performed with two groups of intervention and control and a pretest and posttest design. Seventy-nine nursing students were selected and assigned to the intervention or control groups by random sampling. Virtual education of the information literacy was uploaded on a website in the form of six modules delivered in four weeks. Questionnaires of demographic information and information literacy for EBP were used to collect data before and one month after the virtual education.

Results: The results showed no significant difference between the control and intervention groups in all dimensions of information literacy competency in the pre-test stage. In the post-test, the virtual education improved dimensions of information seeking skills $(t=3.14, p=0.002)$ and knowledge about search operators $(t=39.84, p=0.001)$ in the intervention groups compared with the control group. The virtual education did not have any significant effect on the use of different information resources and development of search strategy with assessing the frequency of selecting the most appropriate search statement in the intervention group.

Conclusion: Virtual education had a significant effect on information seeking skills and knowledge about search operators in nursing students. Nurse educators can benefit from our experiences in designing this method for the use of virtual education programs in nursing schools. Given the lack of effectiveness of this program in using different information resources and development of search strategy, nurse educators are recommended to train information literacy for EBP by integrating several approaches such as virtual (online and offline) and face-to-face education.
\end{abstract}

Keywords: Electronic-learning, Information literacy, Evidence-based nursing, Nursing students, Virtual learning

\footnotetext{
*Correspondence: j.farokhzadian@kmu.ac.ir; farokhzadian2010@yahoo.com

${ }^{4}$ Nursing Research Center, Kerman University of Medical Sciences, PO

Box 7716913555, Haft-Bagh Highway, Kerman, Iran

Full list of author information is available at the end of the article
} original author(s) and the source, provide a link to the Creative Commons licence, and indicate if changes were made. The images or other third party material in this article are included in the article's Creative Commons licence, unless indicated otherwise in a credit line to the material. If material is not included in the article's Creative Commons licence and your intended use is not permitted by statutory regulation or exceeds the permitted use, you will need to obtain permission directly from the copyright holder. To view a copy of this licence, visit http://creativecommons.org/licenses/by/4.0/. The Creative Commons Public Domain Dedication waiver (http://creativeco mmons.org/publicdomain/zero/1.0/) applies to the data made available in this article, unless otherwise stated in a credit line to the data. 


\section{Background}

Evidence-based practice (EBP) has been accepted as an important concept in nursing and is quickly becoming the norm for effective nursing practice globally [1]. EBP is a decision-making approach to patient care that integrates the most current and valid research findings, the nurse's clinical expertise, the client's values and preferences, and available resources in making decisions. The benefits of EBP include nurses' improved practical knowledge, patient-centered care with better patient outcomes, reduced occurrence of adverse events, reduced patient care costs, and health facility $[2,3]$.

Scientific evidence for EBP can be obtained by systematic and structured searches in retrieval systems, bibliographic databases, and clinical guidelines, which require retrieval skills in database searching and information literacy competency [2, 4]. Information literacy competency is the ability to recognize when information is needed, determine the amount of information needed, to retrieve information efficiently, and to evaluate, classify, and store information sources [5]. Information literacy competency is the ability to develop appropriate research questions, perform a search, appraise the relevant literature, and evaluate the transferability of research evidence into clinical practice and we know that it is critical to apply EBP successfully $[6,7]$.

Establishing information literacy competency in nursing students is vital for the promotion of EBP [8]. Nurse educators should develop nursing students' competencies for EBP and then motivate them to deliver the highest quality of care using EBP [9]. Applying the effective strategies for teaching EBP competencies in theory and practice, they also have a fundamental role in developing information literacy competency among students [3]. Unfortunately, efforts to raise nursing students' information literacy in the past years have had minimal success because experts and educators could not agree on effective strategies for nursing education and teaching of nursing information literacy [10]. Consequently, there are gaps in the integration of information literacy competency into nursing education [11]. In some studies, nursing students and newly graduated nurses reported that the training they received in nursing schools were insufficient, and they were not competent in almost all areas of informatics. These studies suggested that information literacy competency had to be improved through informatics curricula [11-13]. Moreover, researchers have reported that nursing schools do not have a standard for the type and complexity of computer skills required for nursing students. [14]. They also reported that factors and barriers affecting a student's information literacy competency including, lack of information literacy in curriculum, confusing definitions of informatics, and nurse educators' lack of informatics skill all might contribute to the student's competency [13]. A systematic review reported that a lack of critical appraisal and advanced literature search skills might contribute to the negative attitudes towards EBP, which can be minimized by appropriate teaching of these skills [6].

It is noteworthy that there is an ongoing transition from traditional teaching and learning to more self-directed learning in nursing education due to the development of the Internet, learning platforms, and new technology [15] and change of the student population to digital natives. However, researchers have paid less attention to teaching strategies such as online teaching/learning and blendedlearning about information literacy competency in Asian countries [10]. In addition, we are entering into a new phase of the evolution in academia and higher education known as "online and digital universities". Digitalization in higher education allows streaming lectures online or enables professors and students to interact through virtual education [16]. Virtual education is a novel educational approach, which can facilitate simple and inexpensive access to educational resources and services through communication technologies (e.g., electronic devices) regardless of time and place [17].

Literature review showed that few studies implemented a training program to improve information literacy competency among students and reported that students' information literacy competency increased after a training program. For example, Liou et al. tried to develop a blended course to improve nursing students' information literacy competency in Taiwan. The majority of students with a positive perception of the teaching strategies expressed that they understood more about information literacy and applied information literacy skills in nursing [10]. A meta-analysis in Iran showed that virtual education was as effective as traditional education. Among different educational technologies, multimedia education, e-learning, and computer-mediated learning had significant effects on medical education. The educational technologies were more effective in the virtual education groups compared with the controls without virtual education [17]. Another study proposed various strategies for the incorporation of EBP competencies into undergraduate nursing education. Nurse educators can use strategies such as debates, social media, simulations, learning modules, game-based learning, workshops and training sessions. None of these strategies are superior to others in terms of teaching EBP [3].

\section{Problem statement}

Health care in Iran has markedly improved over the last 25 years. The Iranian health care system aims to be evidence-based and patient-centered, which requires 
ongoing improvement of the quality of health care professional education. Nursing students need to be prepared for EBP competencies. Insufficient attention has been paid to teaching of information literacy competency in virtual nursing education, especially in middle- and low-income countries. Furthermore, virtual learning strengthens the traditional approaches to education, but there is no evidence of the evaluation of this method. Assessment of the students' information literacy competency for EBP after virtual education can help adjust curricula to students' educational needs. Regarding the importance this issue and the scarcity of the related studies in Iran, this study aimed to evaluate the impact of a training program on information literacy for EBP among the undergraduate nursing students in Iran.

\section{Methods}

\section{Study design and setting}

This interventional study with a pretest-posttest design was conducted in a Nursing School affiliated with Kerman University of Medical Sciences in southeast of Iran.

The bachelor's degree in Iran includes theoretical and practical courses in 8 semesters over four years in the university and educational hospitals. The undergraduate nursing curricula at the time of this study included 1.5 credits of research in nursing ( $34 \mathrm{~h}$ in third semester) and one credit of information technology in nursing $(26 \mathrm{~h}$ in the first semester). According to the current curricula, the participants of this study did not receive educations related to information literacy competency.

\section{Study population and sampling}

The target population of this study included all undergraduate nursing students $(\mathrm{N}=136)$ in the sixth and eighth semesters. The sample size was 80 participants by using the sample size formula that were divided randomly into intervention and control groups (40 students in each group) and equally selected from each of the semesters. Inclusion criteria included the nursing students who passed credits of research in nursing and information technology in nursing and started learning in the clinical settings. The students who were transferred to another university or failed to complete the questionnaires for any reason and guest students were excluded. Finally, 79 students completed the questionnaires and one student of the intervention group did not complete the course (response rate $=98.75 \%$ ), (Fig. 1).

\section{Instruments}

The instrument used in this study consisted of two questionnaires. The first one was about the nursing students' demographic information such as gender, age, so on (Table 2).
The second questionnaire was about information literacy competency for EBP, which was part of a questionnaire namely "Perceptions of Nurses of EBP" and was developed in the previous studies $[18,19]$. This questionnaire composed of two sections. The first section concerned about the use of different information resources by nurses, including electronic, printed, and human sources (19 items). These items could be answered on a 5-point Likert scale ranging from "never" to "always". The second section included information searching skills and use of different search features of online databases and web search engines (10 items) on a 5-point Likert scale ranging from "never" to "always". In addition, nurses' knowledge about Boolean /Connectors ('OR ', AND', 'NOT' or 'AND NOT) and Proximity (e.g. W/nn; $\mathrm{PRE} / \mathrm{nn}$ ) operators was assessed. These items could be answered with yes (one point), no (zero point), and not sure (zero point). Finally, nurses were provided with a hypothetical searching topic (Effect of cigarettes on lung cancer) along with five possible search statements. They were asked to search MEDLINE using Boolean operators and select the most appropriate search statement for the given topic. Item 4 was the most appropriate search statement among the 5 available items (Cigarettes OR Smoking OR Tobacco) AND ("Lung Cancer" OR "Lung Tumor" OR "Lung Neoplasm").

We used the Persian version of the questionnaire in this study, which was validated in Iran. The content validity and reliability $(\alpha=0.87)$ of the Persian version of questionnaire was approved by experts [7].

\section{Data collection}

Data were collected by using an anonymous, selfreported, and electronic questionnaire from March to May 2020. To collect data, the first researcher created groups for each of the intervention and control groups in WhatsApp. Informed consent was obtained from students enrolled in the course two weeks before the program. All students in this study had e-mail addresses; therefore, link of questionnaire was sent to e-mails and WhatsApp groups in pre-test (before course) and posttest stages (one month after the course). The instruction of how to fill out the questionnaires was sent to participants' e-mails and WhatsApp groups. To attain the highest response rate, the first researcher spent appropriate time on data collection and determined a deadline to deliver completed questionnaires. In addition, she sent detailed information about how to learn the educational program. Moreover, she coordinated time of educational sessions with participants in the intervention group and reminded them to attend the sessions in the scheduled times. It should be noted that the participants completed questionnaires at e-campus. 


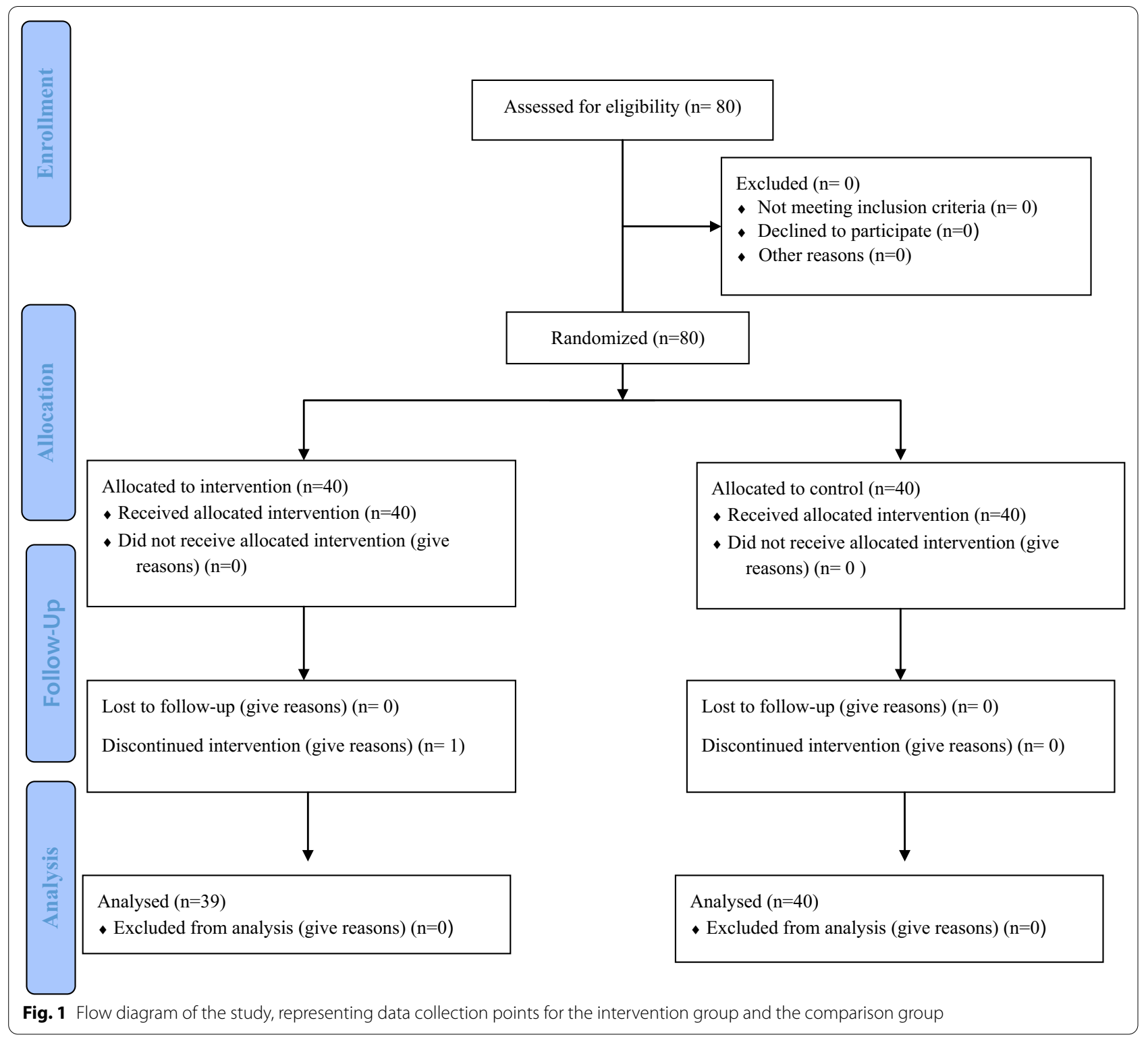

\section{Intervention procedure}

To prepare and develop the course content, the researchers reviewed the literature about information literacy competency and the link between information literacy and EBP in nursing [10, 20-24]. They discussed the extracted topics to achieve a consensus concerning goals and contents and teaching strategies. The researchers employed the standards proposed by the Association of College and Research Libraries as a guide for information literacy competency in higher education and selected essential competencies [24]. The team members provided their experiences and perspectives on required training of students concerning information literacy competency for EBP, as well as teaching-learning activities and educational programs available to informatics literacy in nursing school. This curricular integration also afforded many opportunities for student-centered teaching methods such as evidence-based learning, and inquiry learning. One medical informatics specialist and six nursing faculty members who were not in the research group approved the content validity of the educational content. Finally, two members, one specialized in nursing and the other in medical informatics, prepared topics of the course (Table 1).

The educational materials were uploaded on the website dedicated to this research in form of six modules during four weeks. The participants of the intervention 
Table 1 Topics presented in the modules and students' participation rate in each educational modules

\begin{tabular}{|c|c|c|c|}
\hline Modules & Topics & Missed (\%) & Completed (\%) \\
\hline 1 & $\begin{array}{l}\text { Familiarizing with EBP and understanding of what is involved in EBP } \\
\text { Perceiving the value of EBP in nursing } \\
\text { Learning the level of skills required for undertaking different EBP activities } \\
\text { Discussing and making a possible work plan by using an example according to the steps of EBP } \\
\text { Understanding information literacy and its framework } \\
\text { Explaining various terminologies related to information literacy } \\
\text { Familiarizing with how information technology can be used in education }\end{array}$ & $1(2.50)$ & $39(97.50)$ \\
\hline 2 & $\begin{array}{l}\text { Introducing and orientating variety of information sources including hard print, electronic and human } \\
\text { sources } \\
\text { Developing the skills to obtain e-books, e-journals, and other meaningful information using the library or } \\
\text { the Internet } \\
\text { Demonstrating a variety of electronic search capabilities such as the ways to subscribe and receive free } \\
\text { articles } \\
\text { Determining the most appropriate methods for accessing information electronically: search engines, inter- } \\
\text { faces (the database screens), and content available through a given system }\end{array}$ & $2(5.00)$ & $38(95.00)$ \\
\hline 3 & $\begin{array}{l}\text { Developing skills to criticize/evaluate hardware, software, and websites } \\
\text { Identifying keywords, synonyms, and related terms for the information needed (Medline, etc.) } \\
\text { Describing information needed through key concepts and terms } \\
\text { Demonstrating medical and nursing databases such as Cumulative Index to Nursing \& Allied Health Litera- } \\
\text { ture (CINAHL), PubMed, Scopus,... } \\
\text { Using search strategies in databases such as PubMed and Scopus } \\
\text { Introducing Up to Date, EBSCO,... } \\
\text { Searching articles in Persian databases such as Scientific Information Database)SID(, Medlib, Iranmedex, and } \\
\quad \text { Magiran }\end{array}$ & $1(2.50)$ & $39(97.50)$ \\
\hline 4 & $\begin{array}{l}\text { Doing simple and advanced search, and conducting limited search based on the publication year, full text, } \\
\text { keywords, Medical Subject Headings (MeSH), and using search operators such as AND, OR, NOT and etc } \\
\text { Doing practical exercises. For example, retrieving related articles in databases such as PubMed and Scopus } \\
\text { for "Intubate Patient Care" with related keywords and providing search results }\end{array}$ & $3(7.50)$ & $37(92.50)$ \\
\hline 5 & $\begin{array}{l}\text { Demonstrating abilities and gaining proficiency in search of information, management of information, and } \\
\text { application of various technological tools in presenting information } \\
\text { Determining the nature and extent of the information needed } \\
\text { Explaining the risks and constraints of searching the Internet for needed evidence-based information } \\
\text { Using appropriate search language and parameters for selected system }\end{array}$ & $3(7.50)$ & $37(92.50)$ \\
\hline 6 & $\begin{array}{l}\text { Assessing the quantity, quality, and relevance of the search results to determine whether alternative infor- } \\
\text { mation retrieval systems or investigative methods should be utilized } \\
\text { Evaluating information sources critically and incorporating selected information into their knowledge base } \\
\text { and value system } \\
\text { Comparing various information sources to evaluate reliability, validity, accuracy, authority, timeliness, and } \\
\text { point of view or bias } \\
\text { Synthesizing conclusions based upon information gathered } \\
\text { Using information effectively for a specific purpose individually or as a member of a team } \\
\text { Evaluating outcomes of the use of information }\end{array}$ & $1(2.50)$ & $39(97.50)$ \\
\hline
\end{tabular}

group had a username and password to use the educational content uploaded on the website. The address of the educational website was declared through the communication channels. They were able to access the website off line at any time and place. Reminder messages were sent via WhatsApp and SMS to motivate the use of the website. The communication between students and materials were prepared in the forms of audio file, PowerPoint slides, video tutorials, and textual help, question and answer, hands-on exercise (with examples of literature search), and homework. Students were required to self-study course materials, practice exercises, and discuss issues by E-mail or WhatsApp. Assignments included learning journals and literature search, criticizing website, discussing literacy issues such as academic integrity, and doing a search-based project. Assignments encouraged a sense of involvement in the use of reference materials. All other assignments were submitted to the instructors and their feedbacks were sent to the students via E-mail. The assignments could be resubmitted unlimitedly. While intervention group was provided with additional materials derived from our training course, the control group did not receive this program.

\section{Statistical analysis}

The data were analyzed by using SPSS 21, descriptive statistics (frequency, percentage, mean and standard 
deviation) and inferential statistics (independent samples $t$-test, paired $t$-test, McNemar-test, and chi square). The Kolmogorov-Smirnov test showed that the data followed a normal distribution. The significance level was considered $\leq 0.05$.

\section{Results}

\section{Demographic and professional information}

Table 2 shows demographic and professional information of the study participants. Based on the chi-square test, no significant difference was found between the intervention and control groups in demographic and professional information (Table 2). Data analysis indicated homogeneity of the participants in the two study groups at the baseline in all dimensions of the information literacy for EBP.

\section{Use of different information resources}

According to Table 3, the pretest phase showed no significant difference in the mean scores of use of different information resources between the intervention $(2.70 \pm 0.57)$ and control $(2.63 \pm 0.44)$ groups $(t=1.39$, $p=0.17)$. The results also showed that the control and intervention groups rarely used the electronic information resources with no change at posttest compared with pretest. However, no significant difference was observed between the intervention $(2.53 \pm 0.54)$ and control $(2.71 \pm 0.60)$ groups in the use of different information resources in the posttest $(t=1.33, p=0.18)$. In addition, the paired $t$-test showed no significant change in the use of different information resources between the intervention and control groups at posttest compared with pretest.

\section{Information searching skills}

The pretest phase showed no significant difference in the mean scores of information searching skills and use of the different search features between the intervention $(2.33 \pm 0.74)$ and control $(2.45 \pm 0.64)$ groups $(t=0.68, p=0.50)$. However, a significant difference was observed between the intervention $(2.58 \pm 0.31)$ and control $(2.17 \pm 0.58)$ groups in terms of information searching skills and use of the different search features in the posttest $(t=3.14, p=0.002)$. In addition, the paired $t$-test showed that searching skills and use of the different search features statistically significantly decreased in the control group in posttest compared with pretest (Table 4).

\section{Knowledge about search operators}

The pretest phase showed no significant difference between the intervention $(0.37 \pm 0.09)$ and control $(0.25 \pm 0.08)$ groups in the mean scores of knowledge about search operators $(t=1.54, p=0.12)$. However, a statistically significant improvement was observed in the intervention group $(0.67 \pm 0.07)$ compared with the control group $(0.34 \pm 0.17)$ in terms of knowledge about search operators in the posttest $(t=8.39, p=0.001)$. In addition, the paired $t$-test showed no significant difference in the control group's knowledge about search operators at posttest compared with pretest (Table 5).

Table 2 Comparison of demographic and professional information of the nursing students between the intervention and control groups

\begin{tabular}{|c|c|c|c|c|c|c|c|}
\hline \multirow[t]{2}{*}{ Variables } & \multirow{2}{*}{$\begin{array}{l}\text { Groups } \\
\text { categories }\end{array}$} & \multicolumn{2}{|c|}{ Intervention } & \multicolumn{2}{|c|}{ Control } & \multirow[t]{2}{*}{ Statistic) $\times 2($} & \multirow[t]{2}{*}{$p$-value } \\
\hline & & n & $\%$ & $\mathbf{n}$ & $\%$ & & \\
\hline \multirow[t]{2}{*}{ Gender } & Male & 18 & 64.20 & 27 & 67.50 & 3.60 & 0.06 \\
\hline & Female & 21 & 53.80 & 13 & 32.50 & & \\
\hline \multirow[t]{2}{*}{ Marital status } & Single & 28 & 71.80 & 34 & 85.00 & 2.03 & 0.15 \\
\hline & Married & 11 & 28.20 & 6 & 15.00 & & \\
\hline \multirow[t]{2}{*}{ Work experience in clinical setting (yr) } & None & 15 & 38.50 & 18 & 45.00 & 1.10 & 0.57 \\
\hline & Student work & 24 & 61.50 & 22 & 55.00 & & \\
\hline \multirow[t]{2}{*}{ Attendance at nursing research courses } & Yes & 16 & 42.10 & 10 & 25 & 2.56 & 0.11 \\
\hline & No & 23 & 57.90 & 30 & 75 & & \\
\hline \multirow[t]{2}{*}{ Attendance at computer skills courses } & Yes & 11 & 28.20 & 12 & 30.00 & 0.03 & 0.86 \\
\hline & No & 28 & 71.80 & 28 & 70.00 & & \\
\hline \multirow[t]{2}{*}{ Attendance at information literacy courses } & Yes & 7 & 17.90 & 7 & 17.50 & 0.003 & 0.95 \\
\hline & No & 32 & 82.10 & 33 & 82.50 & & \\
\hline \multirow{3}{*}{$\begin{array}{l}\text { Willingness to use electronic databases and } \\
\text { electronic journals }\end{array}$} & Low & 6 & 15.80 & 12 & 32.40 & 3.19 & 0.20 \\
\hline & Moderate & 18 & 47.40 & 16 & 43.20 & & \\
\hline & High & 14 & 36.80 & 9 & 24.30 & & \\
\hline
\end{tabular}


Table 3 Comparison of the mean scores of the use of different information resources for patient care and clinical decision-making between intervention and control groups at pretest and posttest

\begin{tabular}{|c|c|c|c|c|c|}
\hline Information resources & $\begin{array}{l}\text { Time } \\
\text { Groups }\end{array}$ & $\begin{array}{l}\text { Pretest } \\
M \pm S D\end{array}$ & $\begin{array}{l}\text { Posttest } \\
M \pm S D\end{array}$ & Mean difference & Statistic $\mathrm{t}^{\mathrm{a}} \& \mathrm{p}$ \\
\hline \multirow[t]{3}{*}{ Printed } & Intervention & $2.57 \pm 0.64$ & $2.64 \pm 1.10$ & 0.07 & $\begin{array}{l}t=0.96 \\
p=0.34\end{array}$ \\
\hline & Control & $2.70 \pm 0.72$ & $2.60 \pm 0.49$ & -0.10 & $\begin{array}{l}t=0.73 \\
p=0.47\end{array}$ \\
\hline & $\begin{array}{l}\text { Statistic } \mathrm{t}^{\mathrm{b}} \text { \& } \\
\mathrm{p}\end{array}$ & $\begin{array}{l}t=0.81 \\
P=0.42\end{array}$ & $\begin{array}{l}t=0.30 \\
p=0.76\end{array}$ & & \\
\hline \multirow[t]{3}{*}{ Electronic } & Intervention & $2.36 \pm 0.73$ & $2.27 \pm 0.74$ & -0.09 & $\begin{array}{l}t=0.88 \\
p=0.38\end{array}$ \\
\hline & Control & $2.56 \pm 0.75$ & $2.51 \pm 0.59$ & -0.05 & $\begin{array}{l}t=0.40 \\
p=0.69\end{array}$ \\
\hline & $\begin{array}{l}\text { Statistic } t^{b} \& \\
p\end{array}$ & $\begin{array}{l}t=1.19 \\
p=0.23\end{array}$ & $\begin{array}{l}t=1.60 \\
P=0.11\end{array}$ & & \\
\hline \multirow[t]{3}{*}{ Human } & Intervention & $2.66 \pm 0.52$ & $2.62 \pm 0.92$ & -0.04 & $\begin{array}{l}t=0.25 \\
p=0.80\end{array}$ \\
\hline & Control & $2.87 \pm 0.68$ & $2.84 \pm 0.65$ & -0.03 & $\begin{array}{l}t=0.25 \\
p=0.80\end{array}$ \\
\hline & $\begin{array}{l}\text { Statistic } t^{b} \& \\
\text { \& }\end{array}$ & $\begin{array}{l}t=1.50 \\
p=0.14\end{array}$ & $\begin{array}{l}t=1.54 \\
p=0.13\end{array}$ & & \\
\hline \multirow[t]{3}{*}{ Total } & Intervention & $2.70 \pm 0.57$ & $2.53 \pm 0.54$ & -0.17 & $\begin{array}{l}t=0.53 \\
P=0.60\end{array}$ \\
\hline & Control & $2.63 \pm 0.44$ & $2.71 \pm 0.60$ & 0.08 & $\begin{array}{l}t=0.48 \\
p=0.63\end{array}$ \\
\hline & $\begin{array}{l}\text { Statistic } t^{b} \& \\
p\end{array}$ & $\begin{array}{l}t=1.39 \\
P=0.17\end{array}$ & $\begin{array}{l}t=1.33 \\
P=0.18\end{array}$ & & \\
\hline
\end{tabular}

a Paired $t$-test

b Independent $t$-test

Table 4 Comparison of the mean scores of information searching skills and the use of different search features between intervention and control groups at pre- and posttest

\begin{tabular}{|c|c|c|c|c|c|}
\hline \multirow[t]{2}{*}{ variable } & \multirow{2}{*}{$\begin{array}{l}\text { Time } \\
\text { Groups }\end{array}$} & \multirow{2}{*}{$\begin{array}{l}\text { Pre test } \\
M \pm S D\end{array}$} & \multirow{2}{*}{$\begin{array}{l}\text { Post test } \\
M \pm S D\end{array}$} & \multirow[t]{2}{*}{ Mean difference } & \multirow[t]{2}{*}{ Statistic $t^{a} \& p$} \\
\hline & & & & & \\
\hline \multirow[t]{3}{*}{$\begin{array}{l}\text { Information searching } \\
\text { skills }\end{array}$} & Intervention & $2.33 \pm 0.74$ & $2.85 \pm 0.31$ & 0.52 & $\begin{array}{l}t=2.40 \\
p=0.02\end{array}$ \\
\hline & Control & $2.45 \pm 0.64$ & $2.17 \pm 0.58$ & -0.28 & $\begin{array}{l}t=2.36 \\
p=0.02\end{array}$ \\
\hline & $\begin{array}{l}\text { Statistic } t^{b} \& \\
p\end{array}$ & $\begin{array}{l}t=0.68 \\
p=0.50\end{array}$ & $\begin{array}{l}t=3.14 \\
p=0.002\end{array}$ & & \\
\hline
\end{tabular}

a Paired $t$-test

b Independent $t$-test

Assessing development of search strategy with assessing the frequency of selecting the most appropriate search statement

The students were given a supposed subject "Effect of cigarettes on lung cancer" to assess their skills in developing an effective search statement by using Boolean operators. For simplicity, the certain search features, such as truncations, proximity operators and extensive synonyms were avoided. The students were asked to choose the most appropriate statement among five possible search statements. The pretest phase showed no significant difference between the intervention $(41 \%, \mathrm{n}=16)$ and control $(25 \%, \mathrm{n}=10)$ groups in frequency of selecting the most appropriate search statement $\left(X^{2}=2.30\right.$, $p=0.13)$. In the posttest, the frequency of selecting the most appropriate search statement $(41 \%, \mathrm{n}=16)$ did not change in the intervention group, but it significantly decreased in the control group compared with 
Table 5 Comparison of mean scores of knowledge about search operators between intervention and control groups at pre- and posttest

\begin{tabular}{|c|c|c|c|c|c|}
\hline \multirow[t]{2}{*}{ Variable } & \multirow[t]{2}{*}{ Time Groups } & \multirow{2}{*}{$\begin{array}{l}\text { Posttest } \\
M \pm S D\end{array}$} & \multirow{2}{*}{$\begin{array}{l}\text { Pretest } \\
M \pm S D\end{array}$} & \multirow[t]{2}{*}{ Mean difference } & \multirow[t]{2}{*}{ Statistic $\mathrm{t}^{\mathrm{a}}$ \&p } \\
\hline & & & & & \\
\hline \multirow[t]{3}{*}{$\begin{array}{l}\text { Knowledge about search } \\
\text { operators }\end{array}$} & Intervention & $0.37 \pm 0.09$ & $0.67 \pm 0.07$ & 0.30 & $\begin{array}{l}t=5.08 \\
p=0.001\end{array}$ \\
\hline & Control & $0.25 \pm 0.08$ & $0.34 \pm 0.17$ & 0.09 & $\begin{array}{l}t=1.21 \\
p=0.23\end{array}$ \\
\hline & $\begin{array}{l}\text { Statistic } t^{b} \& \\
p\end{array}$ & $\begin{array}{l}t=1.54 \\
p=0.12\end{array}$ & $\begin{array}{l}t=8.39 \\
p=0.001\end{array}$ & & \\
\hline
\end{tabular}

\footnotetext{
a Paired $t$-test

b Independent $t$-test
}

Table 6 Comparison of frequency of selecting the most appropriate search statement in intervention and control groups at pretest and posttest

\begin{tabular}{|c|c|c|c|c|}
\hline Variable & Groups & $\begin{array}{l}\text { Posttest } \\
\text { n (\%) }\end{array}$ & $\begin{array}{l}\text { Pretest } \\
\mathrm{n}(\%)\end{array}$ & Statistic $^{\mathrm{a}}$ \& \\
\hline \multirow{3}{*}{$\begin{array}{l}\text { Selecting the most } \\
\text { appropriate search } \\
\text { statement }\end{array}$} & Intervention & $16(41)$ & $16(41)$ & $P=1.10$ \\
\hline & Control & $10(25)$ & $8(20)$ & \\
\hline & Statistic $^{b} \& p$ & $\begin{array}{l}x^{2}=2.30 \\
p=0.13\end{array}$ & $\begin{array}{l}X^{2}=4.12 \\
p=0.04\end{array}$ & $p=0.62$ \\
\hline
\end{tabular}

\footnotetext{
a Mc Nemar-test
}

${ }^{b}$ chi square test

intervention group (20\%, $\mathrm{n}=8),\left(X^{2}=4.12, p=0.04\right)$. In addition, the McNemar-test showed that frequency of selecting the most appropriate search statement had no significant change in the control group at posttest compared with pretest (Table 6).

\section{Discussion}

This study evaluated the effect of virtual education on the undergraduate nursing students' information literacy competency for EBP. The results showed that the educational program did not improve significantly the use of different information resources and its dimensions (printed, electronic, and human resources) in the students of the intervention group. The researchers did not find similar interventional studies whose results support the present study. However, several studies [9, 25-28] showed a positive effect of the educational interventions on the use of information resources.

Moreover, the results showed that the control and intervention groups rarely used the electronic information resources, and this educational program could not motivate students in the intervention group to use electronic resources more to search for information on clinical decision-making and EBP. However, a study showed that electronic resources were the most important sources of information for providing health care among postgraduate students [29].

In agreement with these results, researchers in previous studies [7, 30-32] reported that nurses considered their coworkers more efficient than printed information sources because they were more accessible to them. They also believed that human resources would give them an opportunity to discuss clinical decisions and they would gain more confidence [32]. Onyia considered the high cost of electronic resources and Internet access, insufficient library equipment, as well as Internet speed as the reasons for poor use of online resources [31]. In a systematic review, the main barriers reported by nurses related to seeking Internet information were lack of time to search the web, insufficient skills in searching and retrieving information, inability to translate English texts, and the unawareness from the library as a reliable and efficient place for seeking on-line information. Nurses acknowledged lack of appropriate technology infrastructure, little technical and nursing management support, and improper physical location of computers as other barriers of the use of the electronic information resources. Moreover, nurses relied more on their implicit and traditional knowledge during the process of searching and evaluation of clinical guidelines, which is considered risky because it might result in an inadequate and unsafe practice [32].

The results showed that the educational program increased searching skills and use of different search features in the intervention group compared with the control group. Previous studies also have shown the effectiveness of educational interventions in the posttest and improvement of searching skills in participants [9, 33-37]. A literature review reported that nurses were more confident in using Google than using bibliographic databases. PubMed or MEDLINE and CINAHL were the most commonly used bibliographic databases for information retrieval. Although there is an overall global increase in the use of electronic devices, such 
as computers, mobile devices and smartphones, and much information is available to the Internet or databases, the nurses' use of bibliographic databases is significantly low. Nurses still prefer searching information on resources such as Google, as well as consulting and asking coworkers rather than searching bibliographic databases [4].

According to our results, the educational program had a positive effect on the intervention group's knowledge of using Boolean and proximity operators compared with the control group. Several descriptive studies on the use of operators showed the weakness of users [18, 38]. In agreement with our results, a study showed that students' knowledge about search statement and Boolean operator increased after educational course [36]. Owing to the fact that information retrieval systems, including databases and search engines hold millions of records, students should learn correct and advance search, controlled terms, synonyms and terms related to words using Boolean, proximity operators and other search strategies.

This study showed no improvement in the ability of the intervention group after the educational program to develop an online search strategy with selecting the most appropriate search statement. Several studies reported that few nurses selected the most appropriate search statement of the questionnaire using some synonyms of the concepts in a given subject. It should be noted that the questionnaire of the present study was derived from these studies $[7,18,19]$. In agreement with our results, a study implemented an online information literacy tutorial and a face-to-face session for teaching information literacy competency. The results showed that searching skills, including development of search strategy and use of search operators remained unchanged in both method one month later [35]. However, another study reported improvement in the search of information resources and search strategy among nursing master's students through an educational program [39].

The results showed that searching skills and use of different search features statistically significantly decreased in the control group at posttest compared with pretest. Researchers believe that various factors can contribute to the low score of control groups, and the ineffectiveness of this program in the use of different information resources and development of search strategy in intervention group. For example, the educational program was done at the same time as the COVID-19 pandemic. The multiple stressors caused by the COVID-19, the conditions governing the country, the closure of the university, life in quarantine and the unpreparedness of students for this educational method also might contribute to the ineffectiveness of intervention, and we did not examine the impact of them in this study. In addition, readiness, educational backgrounds and practical experiences may affect our results. According to researchers in a study, although digitalization in higher education allows streaming lectures online or enables professors and students to interact in the virtual environments, not everyone is ready for digitalization. Even those young people, who spend much time on playing video games or interacting with others on social network platforms, prefer real classrooms and universities [16]. Other reasons include inadequate skills of professors in using electronic resources, and the age gap between educators (as Digital Immigrants) and nursing students (as native Immigrants) [40]. Educators have challenges with a changing student population, who are mostly younger than 25 years of age and are considered as "digital natives". They respond to information technology much more sufficiently and effectively and their desire to learn with interactive means is stronger than that of the "old scholar" (equal or older than 25 years old). Therefore, innovative teaching strategies are needed in teaching and learning to integrate information literacy into nursing curriculum [10].

In total, the results of this study may be somewhat similar to other studies. However, the discrepancy between some of our results and the abovementioned studies can be due to the differences in community, study population, sampling, randomization and matching of the groups, educational backgrounds and students' familiarity with computers, educational content and method, lack of faceto-face interaction with participants in virtual education, data collection tools, conditions, study setting and time, and nurse educator preparation levels. For example, participants in our study were undergraduate students nursing. In Iran, nursing students are unfamiliar with EBP and have poor understanding of EBP and the importance of using information literacy in EBP. No student is involved in EBP system due to inefficiency of the educational system in the university. Moreover, nurse instructors do not have a proper understanding of EBP and therefore do not emphasize on EBP prerequisites.

Finally, the researchers in this study believe that they cannot achieve effective education by only presentation of the virtual content. It is impossible to achieve educational goals without paying attention to the educational design and models in various formats. Therefore, nurse instructors should achieve effective e-learning by expanding the use of educational design patterns, developing electronic courses and using effective models for improvement of nursing students' information literacy competency for EBP. 


\section{Limitations}

This study had three limitations. First, the study was conducted during the COVID-19 pandemic within a single setting affiliated with a medical university in Iran. We did not have any knowledge about evaluation of information literacy for EBP in students before this time for comparison. Second, we did not assess whether the additional training for information literacy had a detrimental effect on other aspects of nursing education. In this study, we only measured the effectiveness of the educational program with self-report tool and did not evaluate the speed and skills of nursing in practice when developing a search strategy and finding the appropriate resources. Future study can address and evaluate the effectiveness of such educational program in nursing practice. Third, data collection was conducted one month after the intervention. The 3-6 month follow-ups or the post-pandemic follow-up are recommended to have results that are more accurate and to determine the long-term impact of training. Different teaching methods such as online teaching can be applied to determine the best method of teaching information literacy for EBP. Future longitudinal and interventional studies can be performed by using blended methods of education and evaluation of information literacy competency to help determine the actual competency.

\section{Conclusions}

According to the results, virtual education had a positive effect on two aspects of information literacy competency, including information seeking skills and knowledge about search operators in intervention group. The virtual education did not have a positive effect on aspects of the use of information resources and development of search strategy as reported by the students. Future study could evaluate these skills in practice to have better insight regarding the effectiveness of the educational program. However, the use of virtual education and computerbased learning modules, which are cost-effective and offer several benefits in medical education, may not necessarily be the most effective methods for teaching information literacy competency for EBP. Nursing professors and instructors are suggested to combine virtual (online and offline) and face-to-face methods according to conditions and the needs of students to develop educational syllabus in the field of information literacy for EBP and coordinate educational materials in theory and practice. Our experiences in designing this program could be beneficial for developing future educational programs aimed at fostering competencies in information literacy and EBP by nurse educators.

\section{Abbreviations}

CINA HL: Cumulative Index to Nursing \& Allied Health Literature; EBP. Evidence-based practice; MeSH: Medical Subject Headings; SID: Scientific Information Database.

\section{Acknowledgements}

The researchers appreciate all nursing students who spent their time so generously to participate in the study. We also appreciate experts in medical informatics, nursing and medical education that help research team develop the content of the training workshop in this study.

\section{Authors' contributions}

MS, PM, JF and LA contributed to conceiving and designing the research. The data were collected, analyzed, and interpreted by MS, PM, LA, JF, and FF. MS, PM, LA, JF, and FF contributed equally to writing and revising the manuscript and approved the final manuscript. All authors read and approved the final manuscript.

\section{Funding}

This research received no specific grant from any funding agency in the public, commercial, or not-for-profit sectors.

\section{Availability of data and materials}

The data are available upon request to the corresponding author after signing appropriate documents in line with ethical application and the decision of the Ethics Committee.

\section{Ethics approval and consent to participate}

This study was approved by the Ethics Committee of Kerman University of Medical Science with No. 98000090 and the code of ethics No IR.KMU. REC.1398.115. Furthermore, the participants were explained that they could withdraw from the study at all stages with no adverse consequences. Moreover, they were ensured about confidentiality of information. At the beginning of the study, all nursing students signed the written consent forms. Upon completion of the intervention and collection of the second-phase data, participants of the control group were provided with the educational package with the same structure and topics through WhatsApp and e-mails.

Consent for publication

Not applicable.

\section{Competing interests}

The authors declare that they have no competing interests.

\section{Author details}

${ }^{1}$ Department of Community Health Nursing, Kerman University of Medical Sciences, Kerman, Iran. ${ }^{2}$ Nursing Research Center, Department of Critical Care Nursing, Razi Faculty of Nursing and Midwifery, Kerman University of Medical Sciences, Kerman, Iran. ${ }^{3}$ Department of Health Information Sciences, Faculty of Management and Medical Information Sciences, Kerman University of Medical Sciences, Kerman, Iran. ${ }^{4}$ Nursing Research Center, Kerman University of Medical Sciences, PO Box 7716913555, Haft-Bagh Highway, Kerman, Iran. ${ }^{5}$ School of Psychological Sciences, Monash University, Melbourne, Australia.

${ }^{6}$ Centre for Online Health, The University of Queensland, Brisbane, Australia.

Received: 9 September 2020 Accepted: 2 February 2021

Published online: 09 February 2021

\section{References}

1. D'Souza P, George A, Noronha J, Renjith V. Integration of evidence-based practice in nursing education. Manipal J Nurs Health Sci. 2015;1 (1):51-6.

2. Shayan SJ, Kiwanuka F, Nakaye Z. Barriers associated with evidence-based practice among nurses in low-and middle-income countries: a systematic review. Worldviews Evid Based Nurs. 2019;16(1):12-20.

3. Wakibi S: The Evidence Available to Teach Evidence-Based Nursing Practice by Nurse Educators. Tesis for Degree of Masters in Nursing. Doctoral 
dissertation, College of Nursing University of Saskatchewan; 2019. Available from: https://harvest.usask.ca/bitstream/handle/10388/12061/WAKIB I-THESIS-2019.pdf?sequence $=1$.

4. Alving BE, Christensen JB, Thrysøe L: Hospital nurses' information retrieval behaviours in relation to evidence based nursing: a literature review. Health Info Libr J 2018 35.(1):3-23.

5. El Abd MAEH. Innovation behavior levels and its relation with TIGERbased nursing informatics competencies among critical care nurses. Egypt Nurs J. 2017;14(2):59.

6. Iradukunda F, Mayers PM. Rwandan nursing students' knowledge, attitudes and application of evidence-based practice. Curationis. 2020;43(1):1-7.

7. Farokhzadian J, Khajouei R, Ahmadian L. Information seeking and retrieval skills of nurses: Nurses readiness for evidence based practice in hospitals of a medical university in Iran. Int J Med Inform. 2015;84(8):570-7.

8. Vasuki R. The importance and impact of nursing informatics competencies for baccalaureate nursing students and registered nurses. IOSR J Nurs Health Sci. 2016:5(1):20-5

9. Ruzafa-Martínez M, López-Iborra L, Barranco DA, Ramos-Morcillo AJ. Effectiveness of an evidence-based practice (EBP) course on the EBP competence of undergraduate nursing students: a quasi-experimental study. Nurse Educ Today. 2016;38:82-7.

10. Liou S-R, Yu W-C, Tsai H-M, Cheng C-Y. Teaching information literacy in nursing using blended learning pedagogy. Creat Educ. 2015;6(13):1446.

11. Belchez CA: Informatics and faculty intraprofessional assessment and gap analysis of current integration of informatics competencies in a baccalaureate nursing program. Doctor of Nursing Practice Project. The University of Kansas School of Nursing. https:// kuscholarworks.ku.edu University of Kansas; 2019.

12. Choi J, Zucker DM. Self-assessment of nursing informatics competencies for doctor of nursing practice students. J Prof Nurs. 2013;29(6):381-7.

13. Zamarripa-Zoucha A: Evaluation of nursing students' informatics competency using an adapted Self-Assessment of Nursing Informatics Competency Scale (SANICS) tool. Doctoral dissertation, The Ohio State University; 2015.

14. Godsey JA: Towards an Informatics Competent Nursing Profession: Validation of the Self-assessment of Nursing Informatics Competency Scale (SANICS) Before and After Online Informatics Training. ProQuest: Dissertations and Theses database (UMI No: 3717257). University of Hawai'i At Mānoa; 2017.

15. Lejonqvist G-B, Eriksson K, Meretoja R. Evidence of clinical competence by simulation, a hermeneutical observational study. Nurse Educ Today. 2016;38:88-92.

16. Strielkowski W: COVID-19 pandemic and the digital revolution in academia and higher education. Preprints 2020040290 doi: 1020944/preprints2020040290v1 2020.

17. Kaviani H, Mousavi Chelak A: A Meta-Analysis of the Effectiveness of Educational Technologies in Medical Education. Strides in Development of Medical Education 2018, 15(1):0-0.

18. Mokhtar IA, Majid S, Foo S, Zhang X, Theng Y-L, Chang Y-K, Luyt B. Evidence-based practice and related information literacy skills of nurses in Singapore: an exploratory case study. Health Inform J. 2012;18(1):12-25.

19. Majid S, Foo S, Luyt B, Zhang X, Theng Y-L, Chang Y-K, Mokhtar IA. Adopting evidence-based practice in clinical decision making: nurses' perceptions, knowledge, and barriers. J Med Libr Assoc. 2011;99(3):229.

20. Molopyane J, Fourie I. A framework for workplace information literacy in academic contexts. Library Hi Tech. 2015;33(4):562-83.

21. Forster M. Data analysis issues in a phenomenographic investigation into information literacy in nursing practice. Nurse Res. 2013;21(2):30-4.

22. Agyei DD, Kofi CY, Fiankor D, Osman H: The experience of information literacy in evidence-based practice (EBP) among professional nurses in the Ho Municipality of Ghana. Libr philos pract 2015:0_1

23. Frankline M: Assessment of Information Literacy Competencies of Practicing Nurses at Kenyatta National Hospital, Kenya. A research project submitted in partial fulfillment of the degree of Master of Library and Information Science in the School of Education, Kenyatta University Availeb from: ir-librarykuacke 2017, http://www.ala.org/acrl/standards/ informationliteracycompetency

24. Association AL: Information literacy competency standards for higher education 2000. https://alair.ala.org/handle/11213/7668

25. Hecht L, Buhse S, Meyer G. Effectiveness of training in evidence-based medicine skills for healthcare professionals: a systematic review. BMC Med Educ. 2016;16(1):103.

26. Chang SC, Huang CY, Chen SY, Liao YC, Lin CH, Wang HH. Evaluation of a critical appraisal program for clinical nurses: A controlled before-and-after study. J Contin Educ Nurs. 2013;44(1):43-8.

27. Weng Y-H, Kuo KN, Yang C-Y, Lo H-L, Shih Y-H, Chen C, Chiu Y-W. Increasing utilization of Internet-based resources following efforts to promote evidence-based medicine: a national study in Taiwan. BMC Med Inform Decis Mak. 2013;13(1):4.

28. Fiander M, McGowan J, Grad R, Pluye P, Hannes K, Labrecque M, Roberts NW, Salzwedel DM, Welch V, Tugwell P: Interventions to increase the use of electronic health information by healthcare practitioners to improve clinical practice and patient outcomes. Cochrane Database of Systematic Reviews 2015;3

29. Yoon J, Kim S: Internet use by international graduate students in the USA seeking health information. Aslib J Inf Manag 2014.

30. Azmoude E, Farkhondeh F, Ahour M, Kabirian M. Knowledge, practice and self-efficacy in evidence-based practice among midwives in East Iran. Sultan Qaboos Univ Med J. 2017;17(1):e66.

31. Onyia GN: Information Needs and Seeking Behaviour of Nurses in Some Selected Hospitals in Ekpoma, Edo state, Nigeria. International Journal For Research In Health Sciences And Nursing 2016; 2:3

32. Ahmad MM, Musallam R, Allah AH. Nurses and internet health-related information: review on access and utility. Clujul Med. 2018;91(3):266.

33. Myers A, Ishimura Y. Finding sound and score: a music library skills module for undergraduate students. J Acad Librariansh. 2016:42(3):215-21.

34. Bazm S, Mazloomi S: Effect of Blog-based education on increasing information literacy of students in Shahid Sadoughi University of Medical Sciences and Health Services. Journal of Medical Education \& Development 2015;9:4

35. Brettle A, Raynor M. Developing information literacy skills in pre-registration nurses: an experimental study of teaching methods. Nurse Educ Today. 2013;33(2):103-9.

36. Kratochvíl J. Measuring the impact of information literacy e-learning and in-class courses via pre-tests and post-test at the Faculty of Medicine. Masaryk University Mefanet J. 2014;2(2):41-50.

37. Carlock D, Anderson J. Teaching and assessing the database searching skills of student nurses. Nurse Educ. 2007;32(6):251-5.

38. kamali pour m, azad m, ashkani n, esmaeil zadeh z: Students' media literacy and information literacy in para-medicine, nursing and midwifery faculties of Hormozgan University of Medical Sciences. J Mod Med Inf Sci 2017, 3(1):38-45.

39. El-Sayed SH, Hassona FM, Winkelman CW. Effect of a training program on evidence based practice profiles and skills among master nursing students. Zagazig Nurs J. 2014;10(1):1-18.

40. Jouparinejad S, Foroughameri G, Khajouei R, Farokhzadian J. Improving the informatics competency of critical care nurses: results of an interventional study in the southeast of Iran. BMC Med Inform Decis Mak. 2020;20(1):1-12.

\section{Publisher's Note}

Springer Nature remains neutral with regard to jurisdictional claims in published maps and institutional affiliations. 